\title{
Breast-conserving therapy is safe both within $B R C A 1 / 2$ mutation carriers and noncarriers with breast cancer in the Chinese population
}

\author{
Xin Huang ${ }^{1}$, Xiu-Yu Cai ${ }^{2}$, Jia-Qi Liu ${ }^{3}$, Wen-Wen Hao ${ }^{4}$, Yi-Dong Zhou ${ }^{1}$, Xiang Wang ${ }^{3}$, Ying Xu ${ }^{1}$, \\ Chang Chen ${ }^{1}$, Yan Lin ${ }^{1}$, Chang-Jun Wang ${ }^{1}$, Yu Song ${ }^{1}$, Qiang Sun ${ }^{1}$ \\ ${ }^{1}$ Departments of Breast Surgery, Peking Union Medical College Hospital, Xicheng District, Beijing, China; ${ }^{2}$ Department of VIP Region, Sun \\ Yat-Sen University Cancer Center, State Key Laboratory of Oncology in South China, Collaborative Innovation Center for Cancer Medicine, \\ Guangzhou, China; ${ }^{3}$ Department of Breast Surgical Oncology, National Cancer Center/National Clinical Research Center for Cancer/Cancer \\ Hospital, Chinese Academy of Medical Sciences and Peking Union Medical College, Beijing, China; ${ }^{4}$ Sun Yat-sen University Cancer Center, State \\ Key Laboratory of Oncology in South China, Collaborative Innovation Center for Cancer Medicine, Guangzhou, China \\ Contributions: (I) Conception and design: Q Sun, X Huang; (II) Administrative support: Q Sun; (III) Provision of study materials or patients: X \\ Huang, XY Cai, JQ Liu, YD Zhou; (IV) Collection and assembly of data: X Huang, JQ Liu, XY Cai, YD Zhou, X Wang, CJ Wang; (V) Data analysis \\ and interpretation: X Huang, Y Xu, C Chen, Y Lin, Y Song; (VI) Manuscript writing: All authors; (VII) Final approval of manuscript: All authors. \\ Correspondence to: Qiang Sun, MD. Department of Breast Surgery, Peking Union Medical College Hospital, No. 41, Damucang Road, Xicheng \\ District, Beijing 100032, China. Email: sunqiang104095@163.com.
}

Background: $B R C A 1 / 2$ mutation is associated with a high risk of breast cancer, which may preclude breast cancer patients with $B R C A 1 / 2$ mutation from breast-conserving therapy (BCT) [breast-conserving surgery (BCS), followed by radiotherapy, BCT]. It is debatable whether BCT could be a rational choice for Chinese breast cancer patients with a BRCA1/2 mutation.

Methods: The study comprised a cohort of women with invasive breast cancer either receiving BCT or mastectomy following the criteria for the germline BRCA1/2 mutation test. Germline DNA for BRCA1/2 testing was derived from blood samples. Survival analyses were performed. The correlations were analyzed between survival and distinct types of surgery. To compare the survival between different surgical management, Kaplan-Meier univariate analysis and multivariate Cox regression was used.

Results: In BRCA1/2 mutation carriers ( $\mathrm{N}=176)$ and noncarriers $(\mathrm{N}=293), 25 \%$ and $27.3 \%$ of the patients received $\mathrm{BCT}$, respectively $(\mathrm{P}=0.675)$. Patients receiving mastectomy (without radiotherapy or followed by radiotherapy) have larger tumor size $(\mathrm{P}<0.05$ both in $B R C A 1 / 2$ mutation carriers and noncarriers), prognostically worse tumor characteristics including significantly more advanced TNM stage $(\mathrm{P}=0.017$ and $\mathrm{P}<0.0001$ respectively) and more positive lymph nodes $(\mathrm{P}=0.008$ and $\mathrm{P}<0.0001$, respectively) both in BRCA1/2 mutation carriers and noncarriers. Still, more often received systemic therapy has also been observed. After adjustment for clinical-pathological characteristics and systemic treatment, patients who received BCT had a similar breast cancer disease-free survival compared with patients who received mastectomy, both in BRCA1/2 mutation carriers and noncarriers $\left[\mathrm{HR}_{B R C A 1 / 2}=1.17\right.$, confidence interval (CI): 0.57-2.39, $\mathrm{P}=0.68 ; \mathrm{HR}_{\text {noncarriers }}=0.91, \mathrm{CI}: 0.47-1.77, \mathrm{P}=0.79$, respectively). The recurrence free survival after BCT did not differ from mastectomy in BRCA1/2 mutation carriers [BCT, 5-year cumulative recurrence-free survival $($ RFS) $=0.95$, CI: 0.89-1.00; mastectomy, 5-year cumulative RFS =0.93, CI: 0.85-1.00], even better for BCT in noncarriers (BCT, 5-year cumulative RFS =0.67, CI: 0.42-0.89; mastectomy, 5-year cumulative RFS =0.83, CI: 0.71-0.95).

Conclusions: Thus, BCT may be a safe and rational choice for Chinese female breast cancer patients with a BRCA1/2 mutation. However, tumor size, the TNM stage, the number of positive lymph nodes, might be taken into consideration when choosing surgical management. 
Keywords: Breast-conserving therapy (BCT); mastectomy; BRCA1/2 mutation; breast cancer; prognosis

Submitted May 18, 2020. Accepted for publication Jun 12, 2020.

doi: $10.21037 /$ gs-20-531

View this article at: http://dx.doi.org/10.21037/gs-20-531

\section{Introduction}

Breast cancer is the most frequently diagnosed lifethreatening form of cancer in women and the leading cause of cancer deaths among women (1). The integration of genomics into the care of oncology patients has led to an increasing population of patients with breast cancer identified with germline mutations in breast cancer susceptibility genes, requiring physicians to integrate this information into treatment decision making (2). $B R C A$-associated breast cancer is the most common type in hereditary breast cancer, which can differ from sporadic breast cancer both in screening and prevention. However, it is still subject to debate on whether surgical management is also different. Breast-conserving therapy (BCT), breast-conserving surgery (BCS) followed by radiotherapy, is now widely accepted in China for breast cancer patients with unknown gene mutation status. However, BCT remains a relative contraindication to patients with breast cancer with a known or suspected genetic predisposition due to concerns about an increased risk of ipsilateral disease, breast recurrence or contralateral breast cancer, as reported in the National Comprehensive Cancer Network guidelines version 2.2020 (3,4). Even the Society of Surgical Oncology Guideline (2) still moderately recommended BCT to those patients meeting the eligibility. Although long-term follow-up data of the early trials have shown that BCT is associated with a higher rate of local recurrence, no differences in survival were found compared with mastectomy (5-8). Also, the risk of local recurrence has decreased in recent years (9-11).

A genetic test is not as common in China as in western countries. Chinese breast cancer patients with unknown $B R C A$ mutation status have received standard surgical management if eligible, including BCS and mastectomy. Among them, those with BRCA1/2 mutation indeed have received $\mathrm{BCS}$, followed by radiotherapy. Thus, whether BCT is a safe and rational choice for breast cancer patients carrying a mutation in the BRCA1 or BRCA2 gene is still unknown.

Observational studies have reported these findings.
However, study populations are mainly white patients $(3,12)$. For example, Nilsson et al. (12) compared local recurrence (LR) rates and survival between $B R C A 1 / 2$ mutation carriers treated with BCT and those treated with mastectomy. In this cohort study, BRCA1/2 carriers treated with BCT versus mastectomy had a higher risk of LR as first recurrence, although many of the LRs in the BCT group were likely new primary breast cancers. Significant differences were still non found in death resulting from breast cancer, distant recurrence, or overall survival (OS) between the BCT group and the mastectomy group. van den Broek et al. (13) studied the effects of BCT versus mastectomy both in BRCA1/2 mutation carriers compared with noncarriers. In both noncarriers and BRCA1 mutation carriers, patients treated with BCT had similar OS compared with patients treated with mastectomy. However those two studies just involved in White race. As the lifetime risk of breast cancer for a $B R C A$ mutation carrier is with variability based on population studied (14-16), the results can not be applied into Chinese population directly. Cao et al. (17) reported that in Chinese patients with breast cancer who received BCT, there was no statistically significant difference in ipsilateral breast tumor recurrence between BRCA1/2 carriers and noncarriers. However, survival was still not included directly comparing BCT (BCS followed by radiotherapy) with mastectomy (without radiotherapy or followed by radiotherapy) in BRCA1/2 mutation carriers. In addition, for the general breast cancer population, these studies $(6,7)$ did not stratify on BRCA1/2 mutation status.

This study aims to compare the prognostic impact of the two different types of surgery both in BRAC1/2 mutation carriers and noncarriers with breast cancer, BCT (BCS followed by radiotherapy) and mastectomy. The results will yield more direct and convincing conclusions that BCT is a safe choice for the surgical management of Chinese female patients with breast cancer and BRCA1/2 mutations. Thus, finding $B R C A 1 / 2$ mutation status is unnecessary for the choice of surgical management.

We present the following article in accordance with the STROBE reporting checklist (available at http://dx.doi. org/10.21037/gs-20-531). 


\section{Methods}

\section{Ethics}

All the procedures performed in this study involving human participants were conducted following the ethical standards of the institutional and national research committees and with the 1964 Declaration of Helsinki and its later amendments or comparable ethical standards. The study was approved by the Ethics Committee of Peking Union Medical College Hospital (No. ZS 1655), and written informed consent was obtained from all participants.

\section{Study design and participants}

Eligible for a genetic test of $B R C A 1 / 2$ mutation status, a total of 490 Chinese women with primary invasive breast cancer treated with either BCT or mastectomy were recruited from three centers, Peking Union Medical College Hospital, Sun Yat-sen University Cancer Center and Cancer Hospital of Chinese Academy of Medical Sciences, between January 2016 and April 2020. All the patients have been confirmed $B R C A 1 / 2$ mutation status. Patients with a diagnosis of ovarian cancer, except for patients with no ovarian cancer recurrences and $\geq 10$ years elapsed after ovarian cancer diagnosis before breast cancer, were excluded.

At last, stratifying on $B R C A 1 / 2$ mutation status, the $B R C A 1 / 2$ mutation carriers and noncarriers were analyzed on clinical pathological characteristics, breast cancer diseasefree survival, recurrence-free survival (RFS) and breast cancer-specific survival comparing BCT with mastectomy (without radiotherapy or followed by radiotherapy). Current analyses are for follow-up information through April 30, 2020. The TNM stage was classified according to the American Joint Committee on Cancer $8^{\text {th }}$ edition.

\section{BRCA1/2 mutation testing}

The inclusion criteria for the genetic test of $B R C A 1 / 2$ mutation included: (I) triple-negative breast cancer (TNBC) (diagnosed at an age $\leq 60$ years); (II) breast cancer diagnosed at an age $\leq 45$ years; (III) breast cancer diagnosed at any age with at least one close blood relative with a family history including breast cancer, ovarian carcinoma, male breast cancer, prostate cancer, or pancreatic cancer; and (IV) two primary breast cancer primaries including bilateral (contralateral) disease or $\geq 2$ separate ipsilateral primary tumors diagnosed either synchronously or asynchronously.
Screening for $B R C A 1 / 2$ mutations was performed by analyzing genomic DNA extracted from the patients' peripheral blood and capturing targeted sequences followed by high-throughput sequencing. Quality control of the raw data was performed, followed by removing duplicated reads. Clean data were aligned to the hg 19 reference genome using variants obtained by GATK 4.0. Further, the ExAC filtered the variants, the 1,000 Genome project. The filtered variants included untranslated region variants, intronic variants, splicing variants, and exotic variants. All harmful mutations were confirmed by Sanger sequencing in duplicate. Pathogenic mutations and pathogenic mutations are defined as mutations that lead to a truncated protein or that have previously been reported as disease-associated.

\section{Statistical analysis}

Breast cancer cases were allocated to groups according to the most extensive surgery they received for the primary breast cancer: BCT (BCS followed by radiotherapy) and mastectomy (without or followed by radiotherapy). All analyses were performed in the subgroups of $B R C A 1 / 2$ mutation carriers and noncarriers.

The endpoints for treatment comparisons are breast cancer disease-free survival, RFS, and breast cancer-specific survival. The times to these endpoints were calculated from the date of surgery. The events included in our analysis of breast cancer disease-free survival were the first recurrence of disease at a local, regional, or distant site, and the diagnosis of contralateral breast cancer. The events for RFS was the first recurrence of disease at a local and regional site. All the deaths in our cohort were related to breast cancer, which was breast cancer-specific survival. For women with bilateral breast cancer, we were unable to distinguish death or distant recurrence due to the first primary breast cancer from death or distant recurrence due to the second primary breast cancer.

Clinicopathological characteristics were evaluated for an association with the type of surgery within these subgroups, using the Pearson Chi-square test or the Mann-Whitney U test.

Subgroup survival curves were generated via the KaplanMeier method to explore the effects of the different types of surgery on survival for $B R C A 1 / 2$ mutation carriers and noncarriers. Kaplan-Meier univariate analyses and multivariate Cox regressions were used. Factors at or close to a $\mathrm{P}<0.05$ in the univariate analysis, together with some critical clinical confounders $(13,17)$, were used to perform 


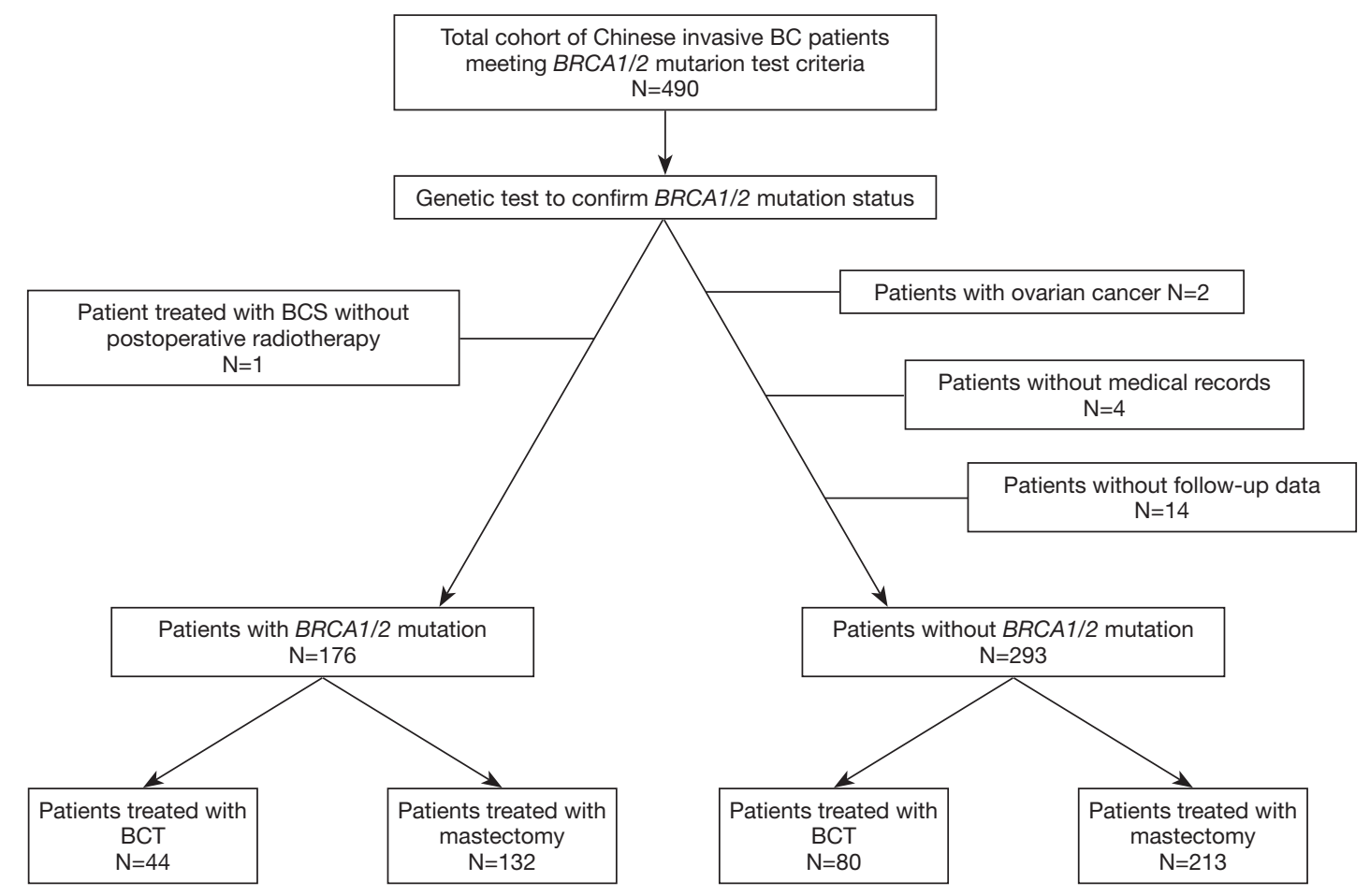

Figure 1 Flow diagram of the patients in the study and analyses.

the multivariate Cox regression to compare survival between different types of surgery both in BRCA1/2 mutation carriers and noncarriers. Factors included for the multivariable analysis were age at diagnosis $(\leq 35,36-45$, and $>45$ years), tumor size $(\leq 2,2-5$, and $>5 \mathrm{~cm})$, TNM stage ( 0 or, I stage, II stage and III stages), estrogen receptor (ER) status (positive/negative), and systemic treatment for the first breast cancer. That is, chemotherapy (no/yes), endocrine therapy (yes/no) and radiotherapy (no/yes) (12).

All statistical analyses were done with SAS version 9.4 (Cary, NC, USA). All statistical tests were two-sided, and a probability level with a random difference of $\mathrm{P}<0.05$ was considered statistically significant.

\section{Results}

Four hundred and ninety breast cancer patients either treated with BCT or mastectomy had been confirmed BRCA1/2 mutation status. Among them, two patients was excluded with a diagnosis of ovarian cancer; one patient was excluded as treated with BCS without postoperative radiotherapy; another four patients were excluded without entire medical records and the other fourteen subjects were lost to follow-up. At last, stratifying on BRCA1/2 mutation status, 176 BRCA1/2 mutation carriers and 293 noncarriers were analyzed (Figure 1). Associations between the distinct types of surgery with clinicopathological characteristics within BRCA1/2 mutation carriers (N=176, Table 1) and noncarriers ( $\mathrm{N}=293$, Table 2) were summarized. The rate of BCT was nearly the same within BRCA1/2 mutation carriers $(25 \%, 44 / 176)$ and noncarriers $(27.3 \%, 80 / 293, \mathrm{P}=0.675)$. Patients treated with BCT appeared to be younger in noncarriers $(\mathrm{P}<0.05)$; however, there was no statistical significance within $B R C A 1 / 2$ carriers $(\mathrm{P}=0.29)$. The patients who received mastectomy more often had larger tumor size $(\mathrm{P}<0.05$ in $B R C A 1 / 2$ mutation carriers and $\mathrm{P}=0.002$ in noncarriers), more positive nodes $(\mathrm{P}=0.008$ and $\mathrm{P}<0.0001$ respectively) and displayed significantly more advanced TNM stages $(\mathrm{P}=0.017$ and $\mathrm{P}<0.0001$, respectively) both in BRCA1/2 mutation carriers and noncarriers. However, the patients treated with mastectomy received systemic endocrine therapy more often compared with those receiving $\mathrm{BCT}(\mathrm{P}<0.05)$ within carriers. While the patients treated with mastectomy received systemic chemotherapy therapy more often $(\mathrm{P}=0.027)$ within noncarriers. Follow-up and events during follow-up are also summarized in Tables 1 and 2 among BRCA1/2 mutation carriers and noncarriers.

There are no significant differences in breast cancer 
Table 1 Association of the types of surgery with clinicopathological characteristics, treatment, and follow-up data, within BRCA1/2 mutation carriers $(\mathrm{N}=176)$

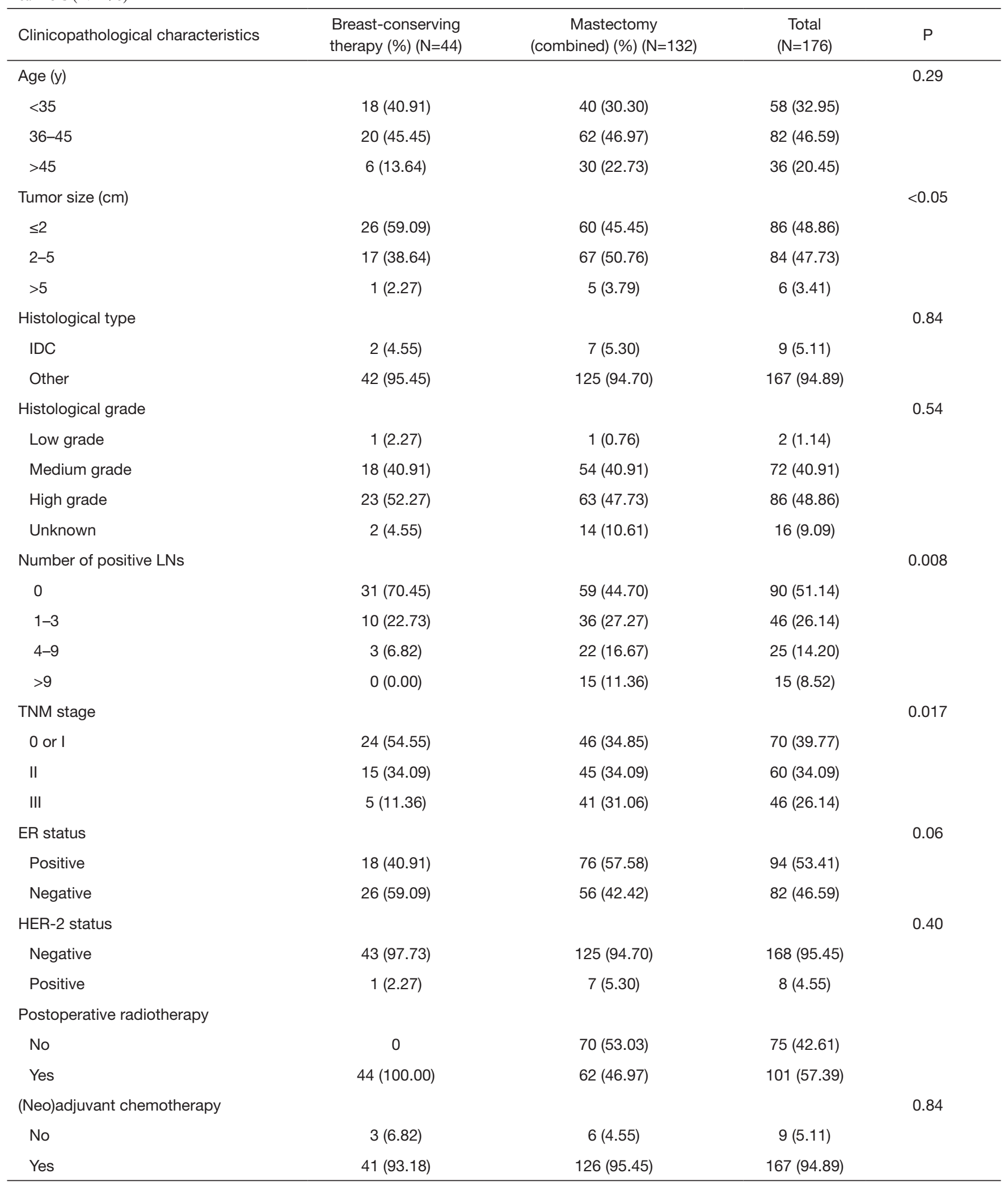

Table 1 (continued) 
Table 1 (continued)

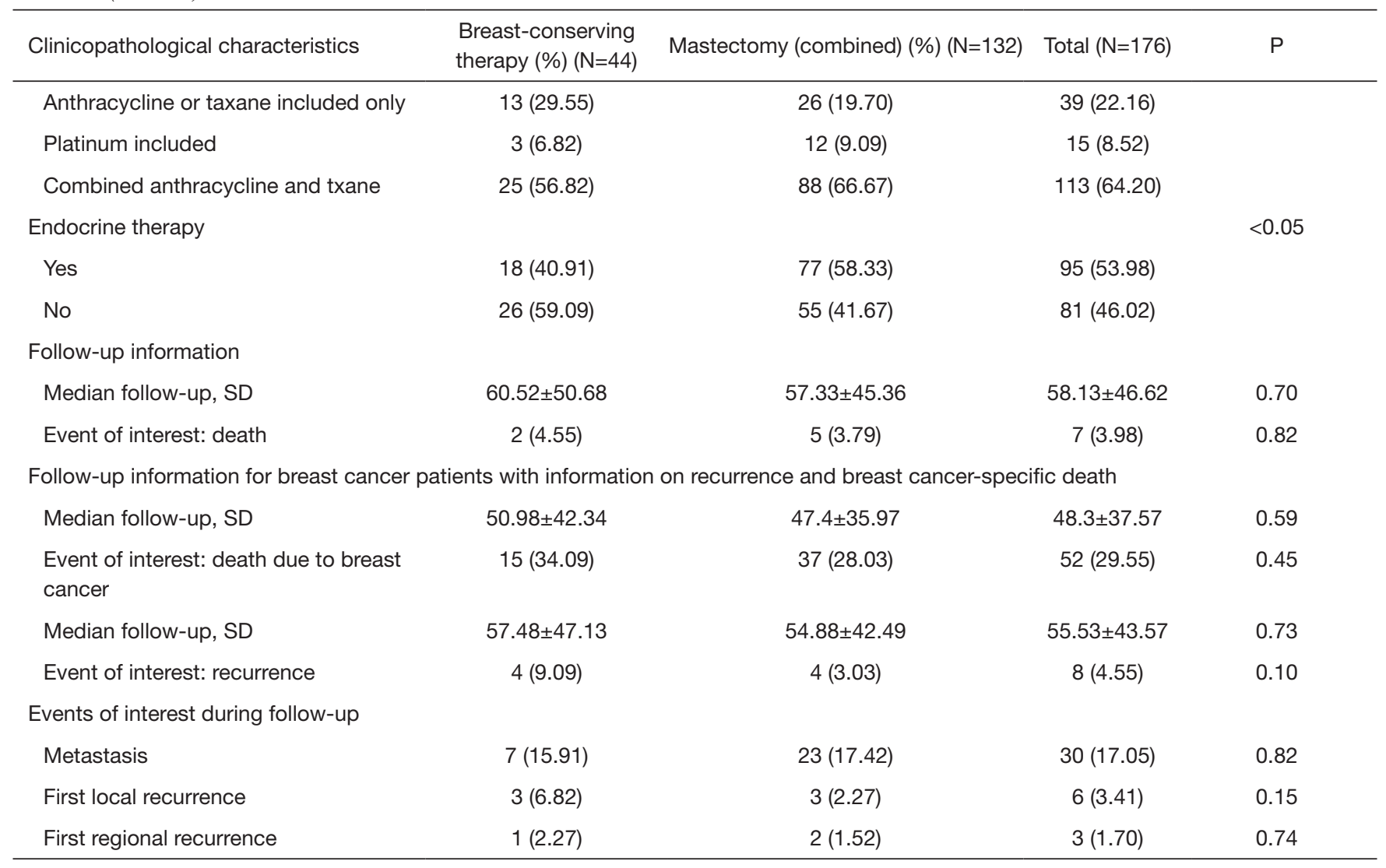

$P$ values were derived from the Pearson Chi-square test for categorical variables and the Mann-Whitney $U$ test for median values.

Table 2 Association of the types of surgery with clinicopathological characteristics, treatment, and follow-up data, within noncarriers (N=293)

\begin{tabular}{|c|c|c|c|c|}
\hline Clinicopathological characteristics & $\begin{array}{l}\text { Breast-conserving } \\
\text { therapy }(\%)(\mathrm{N}=80)\end{array}$ & $\begin{array}{c}\text { Mastectomy } \\
\text { (combined) }(\%)(\mathrm{N}=213)\end{array}$ & $\begin{array}{c}\text { Total } \\
(\mathrm{N}=293)\end{array}$ & $P$ \\
\hline Age & & & & $<0.05$ \\
\hline $36-45$ & $23(28.75)$ & $46(21.60)$ & $69(23.55)$ & \\
\hline$\leq 2$ & $44(55.00)$ & $84(39.44)$ & $128(43.69)$ & \\
\hline $2-5$ & $36(45.00)$ & $106(49.77)$ & $142(48.46)$ & \\
\hline$>5$ & $0(0.00)$ & $23(10.80)$ & $23(7.85)$ & \\
\hline
\end{tabular}

Table 2 (continued) 
Table 2 (continued)

\begin{tabular}{|c|c|c|c|c|}
\hline Clinicopathological characteristics & $\begin{array}{l}\text { Breast-conserving } \\
\text { therapy }(\%)(\mathrm{N}=80)\end{array}$ & $\begin{array}{c}\text { Mastectomy } \\
\text { (combined) }(\%)(\mathrm{N}=213)\end{array}$ & $\begin{array}{c}\text { Total } \\
(\mathrm{N}=293)\end{array}$ & $P$ \\
\hline Number of positive LNs & & & & $<0.0001$ \\
\hline $1-3$ & $10(12.50)$ & $42(19.72)$ & $52(17.75)$ & \\
\hline $4-9$ & $3(3.75)$ & $48(22.54)$ & $51(17.41)$ & \\
\hline TNM stage & & & & $<0.0001$ \\
\hline 0 or I & $39(48.75)$ & $35(16.43)$ & $74(25.26)$ & \\
\hline II & $33(41.25)$ & $87(40.85)$ & $120(40.96)$ & \\
\hline Negative & $53(66.25)$ & $137(64.32)$ & $190(64.85)$ & \\
\hline HER-2 status & & & & 0.62 \\
\hline Negative & $76(95.00)$ & $199(93.43)$ & $275(93.86)$ & \\
\hline Positive & $4(5.00)$ & $14(6.57)$ & $18(6.14)$ & \\
\hline \multicolumn{5}{|l|}{ Postoperative radiotherapy } \\
\hline No & 0 & $98(46.01)$ & 99 (33.79) & \\
\hline Yes & $80(100.00)$ & $115(53.99)$ & $194(66.21)$ & \\
\hline No & $57(71.25)$ & $142(66.67)$ & 199 (67.92) & \\
\hline \multicolumn{5}{|l|}{ Follow-up information } \\
\hline Median follow-up, SD & $31.79 \pm 19.18$ & $31.7 \pm 15.63$ & $31.73 \pm 16.64$ & 0.97 \\
\hline Event of interest: death & $5(6.25)$ & $28(13.15)$ & $33(11.26)$ & 0.10 \\
\hline \multicolumn{5}{|c|}{ Follow-up information for breast cancer patients with information on recurrence and breast cancer-specific death } \\
\hline Median follow-up, SD & $27.21 \pm 15.26$ & $27.71 \pm 14.47$ & $27.58 \pm 14.66$ & 0.79 \\
\hline $\begin{array}{l}\text { Event of interest: death due to } \\
\text { breast cancer }\end{array}$ & $5(6.25)$ & $28(13.15)$ & $33(11.26)$ & 0.10 \\
\hline Median follow-up, SD & $28.6 \pm 14.68$ & $30.28 \pm 14.73$ & $29.82 \pm 14.71$ & 0.38 \\
\hline Event of interest: recurrence & $10(12.50)$ & $17(7.98)$ & $27(9.22)$ & 0.23 \\
\hline
\end{tabular}

$P$ values were derived from the Pearson Chi-square test for categorical variables and the Mann-Whitney $U$ test for median values. 

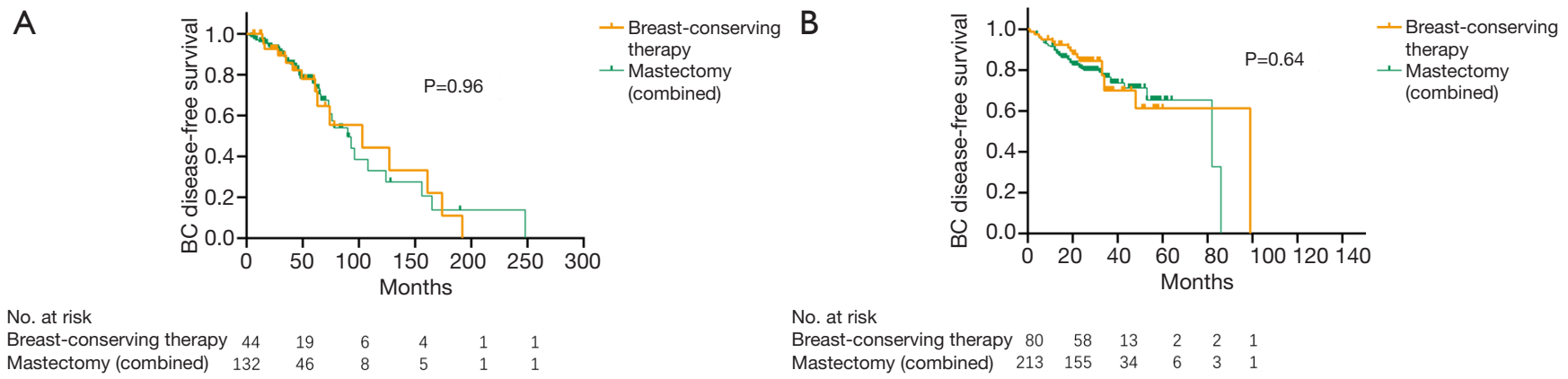

$\begin{array}{lrrrrrr}\text { Breast-conserving therapy } & 44 & 19 & 6 & 4 & 1 & 1 \\ \text { Mastectomy (combined) } & 132 & 46 & 8 & 5 & 1 & 1\end{array}$

No. at risk

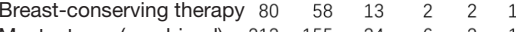

Figure 2 Cumulative Breast cancer disease-free survival for patients stratified by the type of surgery for $B R C A 1 / 2$ mutation, $\mathrm{N}=176$ (A), and noncarriers, $\mathrm{N}=293$ (B). Breast-conserving therapy indicates breast-conserving surgery followed by radiotherapy; Mastectomy (combined) indicates mastectomy (without radiotherapy or followed by radiotherapy); BC indicates breast cancer.

A

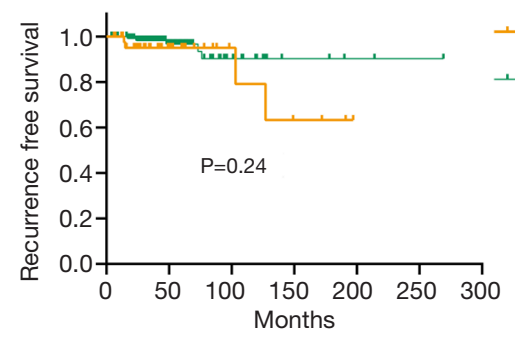

No. at risk

$\begin{array}{lrrrrrr}\text { Breast-conserving therapy } & 44 & 20 & 7 & 4 & 1 & 1 \\ \text { Mastectomy (combined) } & 132 & 56 & 16 & 5 & 3 & 1\end{array}$

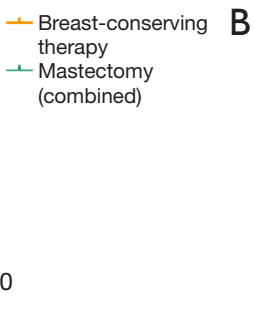

No. at risk

Breast-conserving therapy $\begin{array}{rrrrrr}80 & 63 & 15 & 2 & 2 & 1\end{array}$

Figure 3 Cumulative recurrence-free survival for patients stratified by the type of surgery for $B R C A 1 / 2$ mutation, N=176 (A), and noncarriers, $\mathrm{N}=293$ (B). Breast-conserving therapy indicates breast-conserving surgery followed by radiotherapy; Mastectomy (combined) indicates mastectomy (without radiotherapy or followed by radiotherapy); BC indicates breast cancer.

disease-free survival, RFS and breast cancer-specific survival compared BCT to mastectomy, (without radiotherapy or followed by radiotherapy) both within BRCA1/2 mutation carriers and noncarriers (breast cancer disease-free survival, $\mathrm{P}=0.96$ and $\mathrm{P}=0.64$, Figure $2 ; \mathrm{RFS}, \mathrm{P}=0.24$ and $\mathrm{P}=0.23$, Figure 3; breast cancer-specific survival, $\mathrm{P}=0.87$ and $\mathrm{P}=0.13$, Figure 4, respectively).

Within both $B R C A 1 / 2$ mutation carriers and noncarriers, unadjusted breast cancer disease-free survival was comparable for patients receiving BCT to those receiving mastectomy (without radiotherapy or followed by radiotherapy) $\left[\mathrm{HR}_{B R C A 1 / 2}=1.02\right.$, confidence interval $(\mathrm{CI})=0.55-1.87, P=0.96 ; \mathrm{HR}_{\text {noncarriers }}=0.88, \mathrm{CI}: 0.50$ $1.54, \mathrm{P}=0.65]$. After adjustment for clinicopathological characteristics and treatment, it was still similar $\left(\mathrm{HR}_{B R C A 1 / 2}\right.$ $=1.17, \mathrm{CI}: 0.57-2.39, \mathrm{P}=0.68 ; \mathrm{HR}_{\text {noncarriers }}=0.91$, CI: $0.47-$ 1.77, $\mathrm{P}=0.79$, Table 3).

Within BRCA1/2 mutation carriers, the results for breast cancer-specific survival were in line with those for breast cancer disease-free survival (Table 4). Likewise, HRs for breast cancer-specific survival is still nonsignificant higher both in unadjusted and adjustment for clinicopathological characteristics and

Treatment $\left(\mathrm{HR}_{B R C A 1 / 2}=1.15, \mathrm{CI}: 0.22-5.94, \mathrm{P}=0.87\right.$; $\mathrm{HR}_{B R C A 1 / 2}=1.53$, CI: $0.25-9.17, \mathrm{P}=0.64$, respectively, Table 4) within BRCA1/2 carriers. Interestingly, it appears patients receiving BCT have a nonsignificantly better survival (lower HR) than the patients receiving mastectomy (without radiotherapy or followed by radiotherapy) within noncarriers both in unadjustment and adjustment (HR $=0.49$, CI: $0.19-1.26, \mathrm{P}=0.14 ; \mathrm{HR}_{\text {noncarriers }}=0.53$, CI: $1.17-$ $1.69, \mathrm{P}=0.28$, respectively).

The results for RFS are summarized in Table 5. In noncarriers, the higher risk was observed for patients treated with BCT (5-year cumulative survival, RFS $=0.67$, CI: 0.42-0.89). However, in BRCA1/2 mutation carriers, 
A

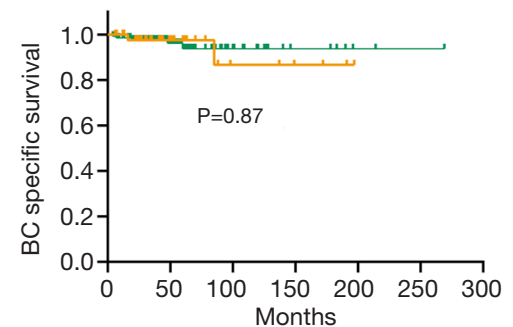

No. at risk

$\begin{array}{llllll}\text { Breast-conserving therapy } & 44 & 20 & 7 & 5 & 1\end{array}$

$\begin{array}{llllll}\text { Mastectomy (combined) } & 132 & 58 & 19 & 7 & 3\end{array}$
B

- Breast-conserving
therapy
- Mastectomy
(combined)

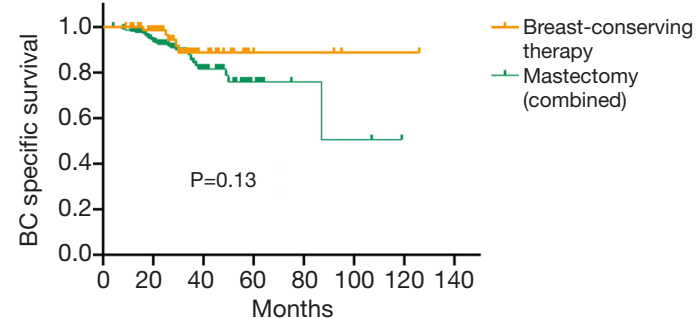

No. at risk

Breast-conserving therapy $80 \quad 65 \quad 19 \quad 5 \quad 5 \quad 5$

$\begin{array}{lrrrrrr}\text { Mastectomy (combined) } & 213 & 177 & 44 & 10 & 4 & 2\end{array}$

Figure 4 Breast cancer specific survival for patients stratified by the type of surgery for BRCA1/2 mutation, $N=176$ (A), and noncarriers, $\mathrm{N}=293$ (B). Breast-conserving therapy indicates breast-conserving surgery followed by radiotherapy; Mastectomy (combined) indicates mastectomy (without radiotherapy or followed by radiotherapy); BC indicates breast cancer.

Table 3 Hazard ratios for breast cancer disease-free survival by the type of surgery, within BRCA1/2 mutation carriers and noncarriers ( $\mathrm{N}=469)$

\begin{tabular}{|c|c|c|c|c|c|c|c|c|c|}
\hline $\begin{array}{l}\text { BRCA1/2 mutation } \\
\text { status }\end{array}$ & Type of surgery & ${ }^{*} \mathrm{HR}(95 \% \mathrm{Cl})$ & $P$ & ${ }^{\dagger} \mathrm{HR}(95 \% \mathrm{Cl})$ & $P$ & ${ }^{\ddagger} \mathrm{HR}(95 \% \mathrm{Cl})$ & $\mathrm{P}$ & *HR (95\% Cl) & $\mathrm{P}$ \\
\hline \multicolumn{10}{|l|}{$B R C A 1 / 2$} \\
\hline & $\begin{array}{c}\text { Breast-conserving } \\
\text { therapy }\end{array}$ & $1.02(0.55-1.87)$ & 0.96 & $1.25(0.60-2.57)$ & 0.55 & $1.17(0.57-2.39)$ & 0.68 & $1.73(0.72-4.16)$ & 0.22 \\
\hline \multicolumn{10}{|l|}{ Noncarriers } \\
\hline & $\begin{array}{l}\text { Mastectomy } \\
\text { (combined) }\end{array}$ & 1.00 & & 1.00 & & 1.00 & & 1.00 & \\
\hline & $\begin{array}{c}\text { Breast-conserving } \\
\text { therapy }\end{array}$ & $0.88(0.50-1.54)$ & 0.65 & $0.92(0.47-1.79)$ & 0.81 & $0.91(0.47-1.77)$ & 0.79 & $1.03(0.44-2.40)$ & 0.95 \\
\hline
\end{tabular}

${ }^{*} \mathrm{HR}$ unadjusted hazard ratio. ${ }^{\dagger} \mathrm{HR}$ hazard ratio adjusted for age, size, stage, and ER. ${ }^{\ddagger} \mathrm{HR}$ additionally adjusted for chemotherapy and endocrine therapy. ${ }^{*} \mathrm{HR}$ additional adjustment for postoperative radiotherapy. $\mathrm{Cl}$, confidence interval; HR, hazard ratio; combined, without radiotherapy or followed by radiotherapy.

Table 4 Hazard ratios for breast cancer-specific survival by the type of surgery, within $B R C A 1 / 2$ mutation carriers and noncarriers $(\mathrm{N}=469)$

\begin{tabular}{|c|c|c|c|c|c|c|c|}
\hline$B R C A 1 / 2$ mutation status & Type of surgery & *HR (95\% Cl) & $\mathrm{P}$ & ${ }^{\dagger} \mathrm{HR}(95 \% \mathrm{Cl})$ & $\mathrm{P}$ & ${ }^{\ddagger} \mathrm{HR}(95 \% \mathrm{Cl})$ & $P$ \\
\hline & Mastectomy (combined) & 1.00 & & 1.00 & & 1.00 & \\
\hline & Breast-conserving therapy & $1.15(0.22-5.94)$ & 0.87 & $1.44(0.22-9.44)$ & 0.70 & $1.53(0.25-9.17)$ & 0.64 \\
\hline \multicolumn{8}{|l|}{ Noncarriers } \\
\hline & Breast-conserving therapy & $0.49(0.19-1.26)$ & 0.14 & $0.48(0.15-1.53)$ & 0.48 & $0.53(0.17-1.69)$ & 0.28 \\
\hline
\end{tabular}

${ }^{*} \mathrm{HR}$ unadjusted hazard ratio. ${ }^{\dagger} \mathrm{HR}$ hazard ratio adjusted for age, size, stage, and ER. ${ }^{\ddagger} \mathrm{HR}$ additionally adjusted for chemotherapy and endocrine therapy. $\mathrm{Cl}$, confidence interval; $\mathrm{HR}$, hazard ratio; combined, without radiotherapy or followed by radiotherapy. 
Table 5 Recurrence free survival, of patients by the type of surgery, within BRCA1/2 mutation carriers and noncarriers $(\mathrm{N}=469)$

\begin{tabular}{|c|c|c|c|c|c|c|c|}
\hline$B R C A 1 / 2$ mutation status & Type of surgery & No. & No. events & Person-years & $\begin{array}{l}\text { Events/1,0000 } \\
\text { person-years }\end{array}$ & 5-y cum survival & $\mathrm{Cl}$ \\
\hline \multicolumn{8}{|l|}{$B R C A 1 / 2$} \\
\hline & Breast-conserving therapy & 44 & 4 & 2,529 & 16 & 0.95 & $0.89-1.00$ \\
\hline \multicolumn{8}{|l|}{ Noncarriers } \\
\hline & Breast-conserving therapy & 80 & 10 & 2,288 & 44 & 0.67 & $0.42-0.89$ \\
\hline
\end{tabular}

5-y cum survival, 5-year cumulative recurrence-free survival; Breast-conserving therapy, combined, without radiotherapy or followed by radiotherapy. $\mathrm{Cl}$, 95\% confidence interval; Events/10,000 person-years, number of events per 10,000 person-years; No. events, number of events during follow-up; No., number of patients at the start of follow-up; Person-years, the sum of person-years of follow-up.

the risk was nearly equal between BCT and mastectomy (BCT, 5 -year cumulative survival, RFS $=0.95$, CI: 0.89-1.00; mastectomy, 5-year cumulative RFS $=0.93$, CI: $0.85-1.00$ ).

\section{Discussion}

In this study, we showed that the prognostic impact of different types of surgery given for the first primary breast cancer on breast cancer disease-free survival, as well as breast cancer-specific survival, is similar within both $B R C A 1 / 2$ mutation carriers and noncarriers. Furthermore, RFS is also similar between $B R C A 1 / 2$ mutation carriers and noncarriers. Our study is the first to evaluate the effect of BCT and mastectomy directly both in BRCA1/2 mutation carriers and noncarriers in the Chinese population. Furthermore, after nearly a decade of practice, the optimal local therapy for women with $B R C A$ associated breast cancer remains controversial (4). Many studies have focused on the white population with much less focus on the Chinese population. BCS has become the standard local therapy for sporadic breast cancer; although it results in increased LR, the survival is equivalent (5). Currently, Chinese patients with breast cancer tend to be younger (18). Thus, many patients request BCT because it has a much lower impact on their life and psychological status compared with mastectomy. Conserving the breasts of patients can have many positive effects on their lives. The result is the same as in the White race reported by van den Broek et al. (13), which showed BRCA1 mutation carriers and noncarriers who received BCT had similar survival as those who received mastectomy. Two other previous studies $(12,19)$ also directly compared the types of surgery between $B R C A 1 / 2$ mutation carriers and found no differences in the overall and breast cancer-specific survival rates for carriers treated with BCT compared with mastectomy. In our study, within noncarriers, even patients treated with BCT seem to have a nonsignificant better breast cancer disease-free survival and breast cancerspecific survival compared to $B R C A 1 / 2$ mutation carriers, which still reminds us of those patients without $B R C A 1 / 2$ mutation that might be more suitable to receive BCT.

Although local recurrence risk was estimated to increase in the BCT group $(5,6,19)$, more and more studies reported there was no increased recurrence for $B R C A 1 / 2$ mutation carriers $(20,21)$, this was following the result of our studies. Two studies were reporting an unadjusted worse survival for BRCA1/2 mutation carriers (22-24), and another two studies did not find a survival difference $(24,25)$. As we showed, 5 -year cumulative RFS was similar, comparing BCT to mastectomy. The reason that why recurrence risk decreased in recent years may be due to the improvement of breastconservation and radiotherapy technology. Furthermore, even if an increase in recurrence risk, it still could not result in a loss of survival; additionally, the literature shows patients who undergo BCT have better survival than patients who undergo mastectomy (26). Current Dutch guidelines recommend BCT as a more suitable management option for early invasive breast cancer compared with mastectomy (27).

We observed a suggestion for a slightly better, though nonsignificant, breast cancer-specific survival for BCT than mastectomy in noncarriers, even when adjusting for clinical-pathological characteristics and systemic treatment. The same results were also reported in the general breast cancer population ever before (28-30). As the breast remained in the patients who received BCT, the 
risk of ipsilateral and contralateral breast cancer increased. Therefore, better survival could not be observed in the BCT group compared to the mastectomy group within BRCA1/2 mutation carriers.

Guidelines recommend some contradictions for BCT, including tumor size and specific tumor and patient characteristics. For example, active connective tissue disease involving the skin was considered a relative contradiction (3).

Our results also showed that patients who received mastectomy had prognostically worse tumor characteristics, including larger tumor size, more advanced TNM stages and more positive lymph nodes. However, survival was still equal between different surgical management groups. Systemic therapy played an important role. As we showed, patients treated with mastectomy received endocrine therapy more often within carriers and chemotherapy more often within non-carriers which was also observed by van den Broek et al. (13). In accordance with the guidelines, tumor size was still the most important factor to be considered for BCT. In addition to that, TNM stage and the status of lymph node were still needed to be considered. Actually those factors in consideration for BRCA1/2 carriers were consistent with sporadic breast cancer patients. Before genetic testing, all patients received the standard systemic treatment, including chemotherapy and radiotherapy, according to the indication for sporadic breast cancer.

Although substantial amounts of data are available for patients in our cohort, insufficient adjustment of our risk estimates may-have occurred due to different characteristics of our treatment subgroups (Tables 1,2). BCS, followed by radiotherapy, is well known as the standard management compared with mastectomy for sporadic breast cancer (31). All patients in this study received radiotherapy after BCS, which accounts for the significant difference in whether radiotherapy was administered to patients in either group (BCT and mastectomy).

Due to the equal survival between different surgical managements within both $B R C A 1 / 2$ mutation carriers and noncarriers, BCT may be a safe and reasonable surgical option for patients with breast cancer with $B R C A$ mutations. Also, a genetic test is unnecessary to select either BCT or mastectomy. Thus, even BRCA1/2 mutation status has not been confirmed before surgery, no need to be nervous. Confirmation of BRCA1/2 mutation status may be more critical to screening and indication for PARP-inhibitors for advanced breast cancer (32).

Although our cohort has stratified on BRCA1/2 mutation status and compared prognostic impact directly on BCT compared to mastectomy, follow-up was still not enough. Except for that, insufficient stratification on BRCA1 and $B R C A 2$ mutation type, more precise conclusions cannot be conducted. Due to the low rate of BCT in both BRCA1/2 mutation carriers $(25 \%)$ and noncarriers $(27.35 \%)$, survival analysis cannot be conducted with the ratio 1 to 1. Therefore, bias may be introduced to some degree. Moreover, only female patients were included in this study. Thus, the results and conclusions may only be proper for female patients with breast cancer with BRCA1/2 mutations.

\section{Conclusions}

In summary, by comparing the survival between BCT and mastectomy among Chinese breast cancer both within $B R C A 1 / 2$ mutation carriers and noncarriers, our results confirm BCT is a safe surgical treatment to offer to BRCA1/2 mutation carriers for the Chinese population. Because all the patients received BCS followed by radiotherapy, adjuvant radiotherapy is necessary after BCS. Due to differences in clinicopathological characteristics between the two groups, tumor size, TNM stage and number of positive lymph nodes should be considered when selecting surgical management for Chinese female patients with breast cancer with $B R C A 1 / 2$ germline mutations.

\section{Acknowledgments}

Funding: This study has been supported by the Fundamental Research Funds for the Central Universities (3332019027), the National Natural Science Foundation of China (81802669 to JL) and CAMS Initiative Fund for Medical Sciences (2016-I2M-1-001 to XW).

\section{Footnote}

Reporting Checklist: The authors have completed the STROBE reporting checklist. Available at http://dx.doi. org/10.21037/gs-20-531

Data Sharing Statement: Available at http://dx.doi. org/10.21037/gs-20-531

Conflicts of Interest: All authors have completed the ICMJE uniform disclosure form (available at http://dx.doi. org/10.21037/gs-20-531). The authors have no conflicts of interest to declare. 
Ethical Statement: The authors are accountable for all aspects of the work in ensuring that questions related to the accuracy or integrity of any part of the work are appropriately investigated and resolved. All the procedures performed in this study involving human participants were conducted following the ethical standards of the institutional and national research committees and with the 1964 Declaration of Helsinki and its later amendments or comparable ethical standards. The study was approved by the Ethics Committee of Peking Union Medical College Hospital (No. ZS 1655), and written informed consent was obtained from all participants.

Open Access Statement: This is an Open Access article distributed in accordance with the Creative Commons Attribution-NonCommercial-NoDerivs 4.0 International License (CC BY-NC-ND 4.0), which permits the noncommercial replication and distribution of the article with the strict proviso that no changes or edits are made and the original work is properly cited (including links to both the formal publication through the relevant DOI and the license). See: https://creativecommons.org/licenses/by-nc-nd/4.0/.

\section{References}

1. Naito Y, Urasaki T. Precision medicine in breast cancer. Chin Clin Oncol 2018;7:29.

2. Salibian AA, Frey JD, Karp NS. Strategies and considerations in selecting between subpectoral and prepectoral breast reconstruction. Gland Surg 2019;8:11-8.

3. National Comprehensive Cancer Network (NCCN) Clinical practices guidelines in oncology, Breast Cancer (2020). Available online: http://www.nccn.org/ professionals/physician_gls/pdf/breast.pdf. Accessed Feberury 52020.

4. Robson M, Svahn T, McCormick B, et al. Appropriateness of breast-conserving treatment of breast carcinoma in women with germline mutations in BRCA1 or BRCA2: a clinic-based series. Cancer 2005;103:44-51.

5. Fisher B, Anderson S, Bryant J, et al. Twenty-year followup of a randomized trial comparing total mastectomy, lumpectomy, and lumpectomy plus irradiation for the treatment of invasive breast cancer. $\mathrm{N}$ Engl J Med 2002;347:1233-41.

6. Veronesi U, Cascinelli N, Mariani L, et al. Twentyyear follow-up of a randomized study comparing breastconserving surgery with radical mastectomy for early breast cancer. N Engl J Med 2002;347:1227-32.
7. Clarke M, Collins R, Darby S, et al. Effects of radiotherapy and of differences in the extent of surgery for early breast cancer on local recurrence and 15-year survival: an overview of the randomised trials. Lancet 2005;366:2087-106.

8. van Dongen JA, Voogd AC, Fentiman IS, et al. Long-term results of a randomized trial comparing breast-conserving therapy with mastectomy: European Organization for Research and Treatment of Cancer 10801 trial. J Natl Cancer Inst 2000;92:1143-50.

9. Aalders KC, Postma EL, Strobbe LJ, et al. Contemporary Locoregional Recurrence Rates in Young Patients With Early-Stage Breast Cancer. J Clin Oncol 2016;34:2107-14.

10. Bosma SC, van der Leij F, van Werkhoven E, et al. Very low local recurrence rates after breast-conserving therapy: analysis of 8485 patients treated over a 28 -year period. Breast Cancer Res Treat 2016;156:391-400.

11. Geurts YM, Witteveen A, Bretveld R, et al. Patterns and predictors of first and subsequent recurrence in women with early breast cancer. Breast Cancer Res Treat 2017;165:709-20.

12. Nilsson MP, Hartman L, Kristoffersson U, et al. High risk of in-breast tumor recurrence after BRCA1/2-associated breast cancer. Breast Cancer Res Treat 2014;147:571-8.

13. van den Broek AJ, Schmidt MK, van 't Veer LJ, et al. Prognostic Impact of Breast-Conserving Therapy Versus Mastectomy of BRCA1/2 Mutation Carriers Compared With Noncarriers in a Consecutive Series of Young Breast Cancer Patients. Ann Surg 2019;270:364-72.

14. Kuchenbaecker KB, Hopper JL, Barnes DR, et al. Risks of breast, ovarian, and contralateral breast cancer for BRCA1 and BRCA2 mutation carriers. JAMA 2017; 317:2402-16.

15. Hartmann LC, Lindor NM. The role of risk-reducing surgery in hereditary breast and ovarian cancer. $\mathrm{N} \mathrm{Engl} \mathrm{J}$ Med 2016;374:454-68.

16. Chen S, Parmigiani G. Meta-analysis of BRCA1 and BRCA2 penetrance. J Clin Oncol 2007;25:1329-33.

17. Cao W, Xie Y, He Y, et al. Risk of ipsilateral breast tumor recurrence in primary invasive breast cancer following breast-conserving surgery with BRCA1 and BRCA2 mutation in China. Breast Cancer Res Treat 2019;175:749-54.

18. Fan L, Strasser-Weippl K, Li JJ, et al. Breast cancer in China. Lancet Oncol 2014;15:e279-89.

19. Pierce LJ, Phillips KA, Griffith KA, et al. Local therapy in BRCA1 and BRCA2 mutation carriers with operable breast cancer: comparison of breast conservation and mastectomy. Breast Cancer Res Treat 2010;121:389-98. 
20. Valachis A, Nearchou AD, Lind P. Surgical management of breast cancer in BRCA-mutation carriers: a systematic review and meta-analysis. Breast Cancer Res Treat 2014;144:443-55.

21. Hallam S, Govindarajulu S, Huckett B, et al. BRCA1/2 Mutation-associated Breast Cancer, Wide Local Excision and Radiotherapy or Unilateral Mastectomy: A Systematic Review. Clin Oncol (R Coll Radiol) 2015;27:527-35.

22. Robson ME, Chappuis PO, Satagopan J, et al. A combined analysis of outcome following breast cancer: differences in survival based on BRCA1/BRCA2 mutation status and administration of adjuvant treatment. Breast Cancer Res 2004;6:R8-R17.

23. Seynaeve C, Verhoog LC, van de Bosch LM, et al. Ipsilateral breast tumour recurrence in hereditary breast cancer following breast-conserving therapy. Eur J Cancer 2004;40:1150-8.

24. Kirova YM, Stoppa-Lyonnet D, Savignoni A, et al. Risk of breast cancer recurrence and contralateral breast cancer in relation to BRCA1 and BRCA2 mutation status following breast-conserving surgery and radiotherapy. Eur J Cancer 2005;41:2304-11.

25. Pierce LJ, Strawderman M, Narod SA, et al. Effect of radiotherapy after breast-conserving treatment in women with breast cancer and germline BRCA1/2 mutations. J Clin Oncol 2000;18:3360-9.

26. Christiansen P, Carstensen SL, Ejlertsen B, et al. Breast conserving surgery versus mastectomy: overall and relative survival-a population based study by the Danish

Cite this article as: Huang $\mathrm{X}$, Cai XY, Liu JQ, Hao WW, Zhou YD, Wang X, Xu Y, Chen C, Lin Y, Wang CJ, Song Y, Sun Q. Breast-conserving therapy is safe both within BRCA1/2 mutation carriers and noncarriers with breast cancer in the Chinese population. Gland Surg 2020;9(3):775-787. doi: $10.21037 /$ gs-20-531
Breast Cancer Cooperative Group (DBCG). Acta Oncol 2018;57:19-25.

27. Guideline for breast cancer. NABONDutch Institute for Healthcare Improvement,. Available online: http://www. oncoline.nl/mammacarcinoom. Accessed September 22016.

28. van Maaren MC, de Munck L, de Bock GH, et al. 10 year survival after breast-conserving surgery plus radiotherapy compared with mastectomy in early breast cancer in the Netherlands: a population-based study. Lancet Oncol 2016;17:1158-70.

29. van Maaren MC, de Munck L, Jobsen JJ, et al. Breastconserving therapy versus mastectomy in T1-2N2 stage breast cancer: a population-based study on 10-year overall, relative, and distant metastasis-free survival in 3071 patients. Breast Cancer Res Treat 2016;160:511-21.

30. Lagendijk M, van Maaren MC, Saadatmand S, et al. Breast conserving therapy and mastectomy revisited: Breast cancer-specific survival and the influence of prognostic factors in 129,692 patients. Int J Cancer 2018;142:165-75.

31. Smith TE, Lee D, Turner BC, et al. True recurrence vs. new primary ipsilateral breast tumor relapse: an analysis of clinical and pathologic differences and their implications in natural history, prognoses, and therapeutic management. Int J Radiat Oncol Biol Phys 2000;48:1281-9.

32. Lee JM, Ledermann JA, Kohn EC. PARP Inhibitors for BRCA1/2 mutation-associated and BRCA-like malignancies. Ann Oncol 2014;25:32-40.

(English Language Editor: J. Chapnick) 